\title{
Cobalt-chitosan: Magnetic and biodegradable heterogeneous catalyst for selective aerobic oxidation of alkyl arenes and alcohols
}

\author{
AHMAD SHAABANI*, MAHMOUD BORJIAN BOROUJENI and \\ MONA HAMIDZAD SANGACHIN \\ Faculty of Chemistry, Shahid Beheshti University, G. C., P. O. Box 19396-4716, Tehran, Iran \\ e-mail: a-shaabani@sbu.ac.ir
}

MS received 12 May 2015; revised 7 August 2015; accepted 8 August 2015

\begin{abstract}
A novel and biodegradable cobalt-chitosan as a magnetic heterogeneous catalyst was synthesized and characterized by XPS, FT-IR, EDX and TEM. Catalytic performance of cobalt- chitosan was tested by aerobic oxidation of alkyl arenes and alcohols. The results show that the catalyst exhibits excellent conversion for selective aerobic oxidation of various alkyl arenes, primary and secondary alcohols with air as the only oxidant. The catalyst can be easily separated by magnetic devices and reused for 5 runs without appreciable loss of activity.
\end{abstract}

Keywords. Cobalt; chitosan; heterogeneous catalyst; magnetism; aerobic oxidation; alkyl arene.

\section{Introduction}

The selective oxidation of alkyl arenes and alcohols into the corresponding carbonyl compounds is an important goal in synthesis of fine chemicals. ${ }^{1}$ From green chemistry point of view, improving methods for oxidation which use clean oxidants and reduce the amount of waste are important. ${ }^{2}$ Numerous homogeneous catalysts are widely used for aerobic oxidation, however they have drawbacks such as tedious catalyst separation and pollution of the product with catalyst. ${ }^{3-9}$ Immobilization of homogeneous catalyst on the solid supports simplifies the reaction procedure and increases the stability and recyclability of the catalyst. ${ }^{10}$ In a few catalysts that were developed for aerobic oxidation, noble metal-based catalysts, such as $\mathrm{Au}, \mathrm{Pt}, \mathrm{Pd}, \mathrm{Ru}$, etc., are widely used. However, these catalysts are expensive and the reaction conditions such as strongly basic medium often reduce the selectivity of the reaction. ${ }^{11-20}$

Using low cost and nontoxic base metal such as cobalt as catalyst is worthwhile. Cobalt, due to strong capability for dioxygen activation, is attractive in aerobic oxidation. ${ }^{21}$ Cobalt-based catalyst systems are widely used for oxidation of alcohols, ${ }^{22-31}$ sulfides, ${ }^{32}$ oximes $^{33}$ and alkylbenzenes. ${ }^{34,35}$ Recently, to overcome the drawbacks of homogeneous cobalt-based catalysts, much attention has been focused on immobilization of

*For correspondence cobalt onto inorganic solid supports such as $\mathrm{TiO}_{2},{ }^{31}$ silica, ${ }^{36} \mathrm{ZnO}^{37}$ zeolites, ${ }^{38,39}$ Montmorillonite, ${ }^{40}$ and commercial carbon. ${ }^{41}$

Natural organic polymers such as cellulose and chitosan are interesting materials as suitable supports for catalytic applications due to low cost and high surface area. These polymers have interesting properties such as biodegradability, biocompatibility, and non-toxicity. ${ }^{42,43}$ Chitosan is a natural polysaccharide prepared by deacetylation of chitin. Chitin is a natural polymer obtained from crabs, insects and shrimps. Amine and hydroxyl groups in chitosan chain can chelate with metal ion. Using chitosan as a support was reported due to its advantage properties such as low toxicity and high affinity for transition metal ions in solution. ${ }^{44-50}$ It is important to note that not only cobalt was easily separated from chitosan by chemical treatment or carbonization but also exhibited good reusability by virtue of isolation using an external magnet.

In continuation of our efforts to synthesize of chemically supported heterogeneous cellulose- and graphenebased heterogeneous catalysts for organic reactions, ${ }^{51,52}$ herein we report the synthesis and characterization of a new biodegradable and magnetic cobalt-based heterogeneous catalyst supported on chitosan, which is highly effective for selective aerobic oxidation of alkyl arenes, primary and secondary aromatic alcohols. The catalyst can be easily separated by magnets and reused up to five times without loss of activity. 


\section{Experimental}

\subsection{Materials and equipment}

Chitosan (degree of deacetylation $=88 \%, \mathrm{Mv}=$ 320000) was purchased from Sigma-Aldrich. Other chemicals were purchased from Merck and used without further purification.

X-ray powder diffraction (XRD) data were collected on a STOE STADI P with scintillation detector, secondary monochromator using $\mathrm{Cu} \mathrm{K}_{\alpha}$ radiation. Cobalt determination was carried out on Flame atomic
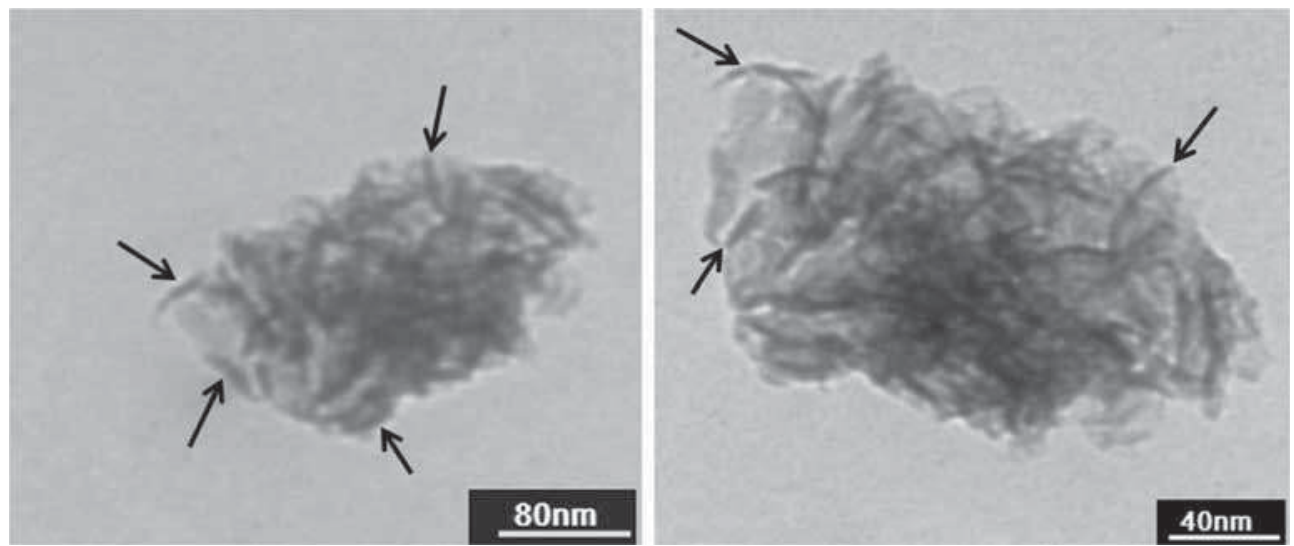

Figure 1. HR-TEM images of cobalt-chitosan. Cobalt particles are shown by arrows.

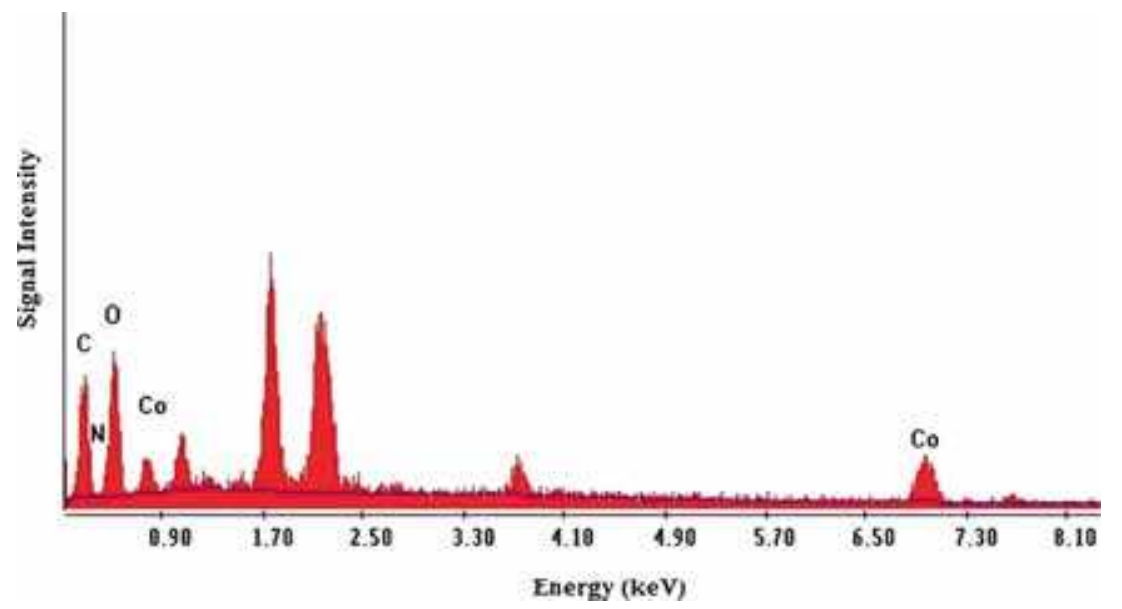

Figure 2. EDX results of cobalt -chitosan.
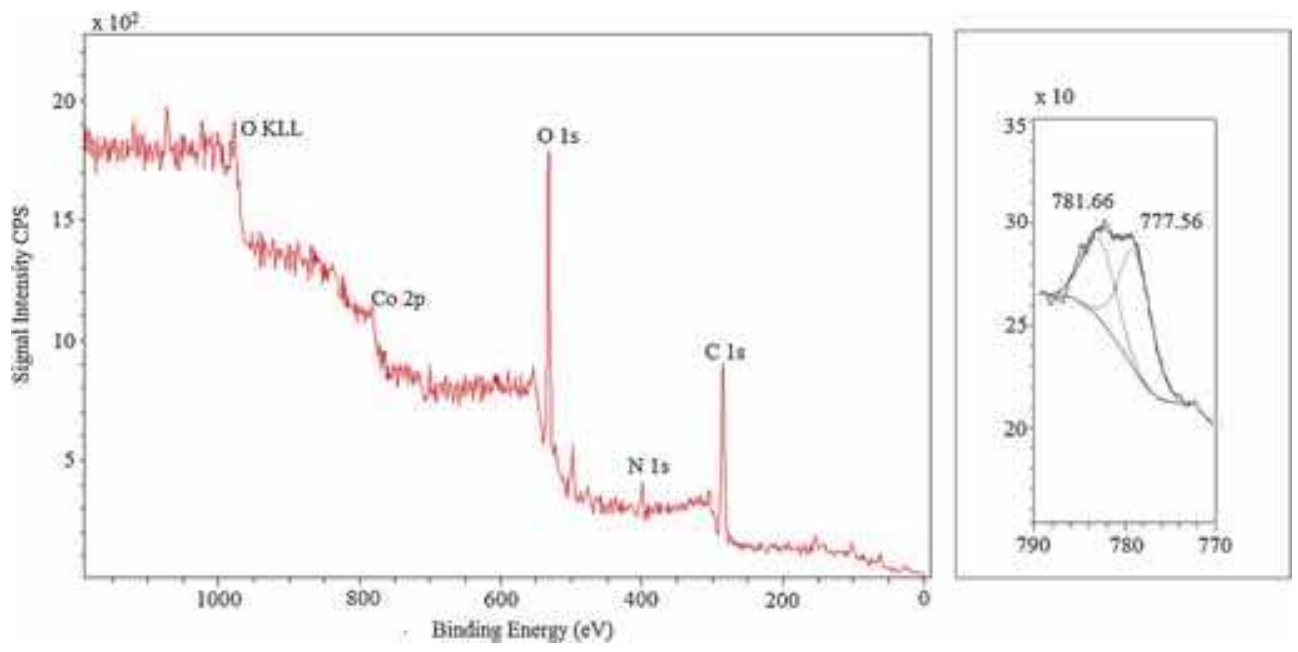

Figure 3. XPS spectrum of cobalt-chitosan. 


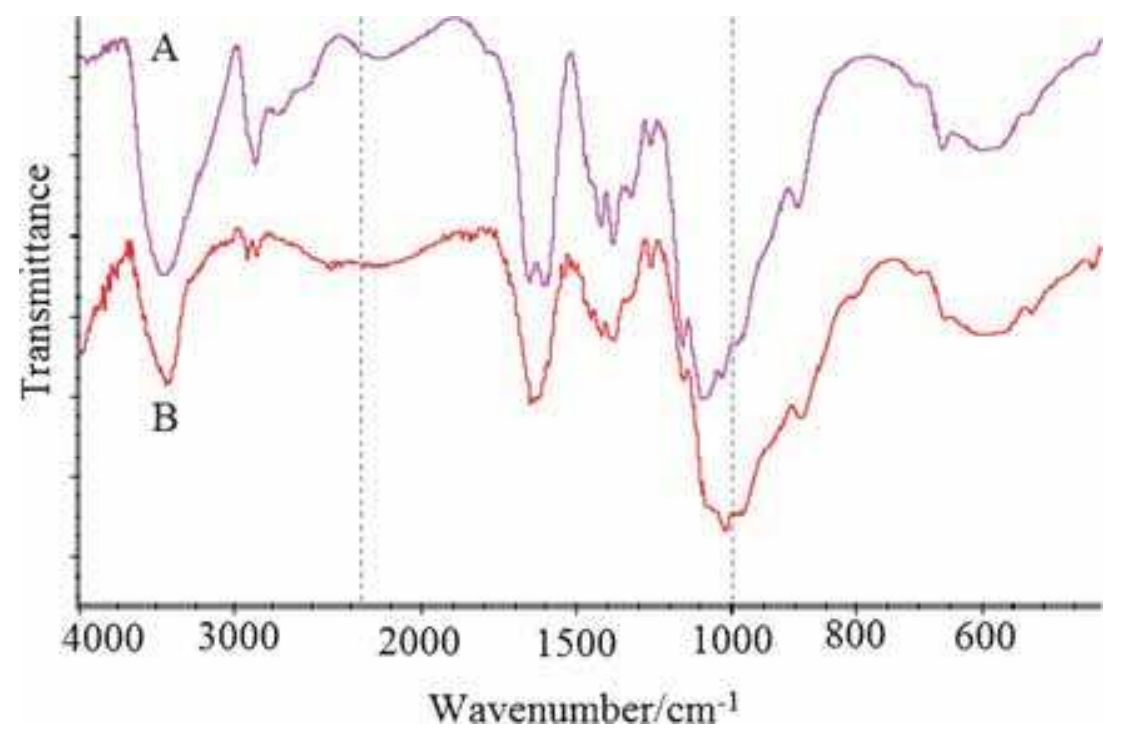

Figure 4. Infrared spectra of chitosan (A) and cobalt-chitosan (B).

absorption spectroscopy (FAAS, Shimadzu model AA680 atomic absorption spectrometer) with a Co hollow cathode lamp at $240.7 \mathrm{~nm}$, using an air-acetylene flame. Transmission electron microscopy (TEM) analysis was performed by LEO $912 \mathrm{AB}$ electron microscope in an ultra-high vacuum. For TEM imaging, a small amount of the catalyst was dispersed in ethanol and sonicated for $15 \mathrm{~min}$ and then a drop of solution was deposited on carbon- supported $\mathrm{Cu}$ grid. Products were analyzed using Agilent 7890A Gas Chromatograph. Internal standard method was used to measure the amount of the obtained products. 1-Bromodecane was used as an internal standard. XPS analysis was performed using a VG multilab 2000 spectrometer (Thermo VG scientific) in an ultra-high vacuum. Thermogravimetric analysis
(TGA) was done using STA 1500 instrument heating at the rate of $10^{\circ} \mathrm{C} \mathrm{min}{ }^{-1}$ in air.

\subsection{Catalyst preparation}

Chitosan $(0.5 \mathrm{~g})$ was suspended in $50 \mathrm{~mL}$ of water. To this suspension, $15 \mathrm{~mL}$ of $0.1 \mathrm{M}$ solution of cobalt (II) chloride hexahydrate was added and stirring continued for $4 \mathrm{~h}$ at room temperature. Then, $5 \mathrm{~mL}$ of solution of $\mathrm{NaBH}_{4}$ (2.2 mmol, $0.08 \mathrm{~g}$ ) was added dropwise to control the reduction process and prevent agglomeration of cobalt particles under vigorous stirring to the suspension during $4 \mathrm{~h}$. The reaction solution stirred at ambient temperature for $2 \mathrm{~h}$ to complete reaction under an inert atmosphere. Finally, the black suspension was

Table 1. Effects of the solvent, temperature, reaction time, amount of catalyst and initiator on oxidation of alkyl arenes using cobalt-chitosan.

\begin{tabular}{|c|c|c|c|c|c|c|}
\hline Entry & Solvent & Initiator & Amount of catalyst (mol \%) & Time (h) & Temperature $\left({ }^{\circ} \mathrm{C}\right)$ & Yield $(\%)^{\mathrm{a}}$ \\
\hline 1 & 1,2-dichlorobenzene & NHPI & 1 & 8 & 80 & 50 \\
\hline 2 & 1,2-dichlorobenzene & NHPI & 2 & 7 & 80 & 60 \\
\hline 3 & 1,2-dichlorobenzene & NHPI & 3 & 5 & 80 & 70 \\
\hline 4 & 1,2-dichlorobenzene & NHPI & 4 & 3 & 80 & 85 \\
\hline 5 & 1,2-dichlorobenzene & NHPI & 5 & 2 & 80 & 95 \\
\hline 6 & 1,2-dichlorobenzene & - & 5 & 8 & 80 & Trace \\
\hline 7 & 1,2-dichlorobenzene & NHPI & 5 & 2 & 70 & 60 \\
\hline 8 & n- heptan & NHPI & 5 & 2 & 80 & 60 \\
\hline 9 & n- hexan & NHPI & 5 & 2 & 60 & 10 \\
\hline 10 & EtOH & NHPI & 5 & 8 & 70 & 0 \\
\hline 11 & $\mathrm{H}_{2} \mathrm{O}$ & NHPI & 5 & 8 & 100 & 0 \\
\hline
\end{tabular}

Reaction conditions: diphenylmethane ( $1 \mathrm{mmol})$, NHPI (1 mol \%), $10 \mathrm{~mL}$ solvent, air

${ }^{\text {a }}$ GC Yield 
separated by an external magnet, and the catalyst washed with deionized water and dried under vacuum at $60^{\circ} \mathrm{C}$. The catalyst was characterized by TGA, EDX, XPS and TEM.

\subsection{General procedure for oxidation of alkyl arenes}

Alkyl arenes $(1 \mathrm{mmol})$ were added in a two roundbottomed glass flask containing a mixture of cobalt-chitosan
$(5 \mathrm{~mol} \%, 0.023 \mathrm{~g})$ and NHPI (1 mol \%, $0.016 \mathrm{~g})$ in $10 \mathrm{~mL} \mathrm{1,2-dichlorobenzene.} \mathrm{The} \mathrm{flask} \mathrm{was} \mathrm{fitted}$ with a reflux condenser and mixture was heated at $80^{\circ} \mathrm{C}$ with continuous bubbling of air with flow rate of $15 \mathrm{~mL}$ $\mathrm{min}^{-1}$. After completion of the reaction (progress of the reaction followed by TLC), catalyst was separated by an external magnet and the reaction mixture was analyzed by gas chromatography.

Table 2. Aerobic oxidation of alkyl arenes with cobalt-chitosan.

(\%)

Reaction conditions: alkyl arene $1 \mathrm{mmol}, 5 \mathrm{~mol} \%$ catalyst, $0.023 \mathrm{~g}$ ), and NHPI ( $1 \mathrm{~mol}$ $\%, 0.016 \mathrm{~g}$ ) in $10 \mathrm{~mL}$ 1,2-dichlorobenzene

${ }^{a} \mathrm{GC}$ Yield 
Table 3. Effects of the solvent, temperature and base on oxidation of phenylethyl alcohol using cobalt-chitosan. ${ }^{\mathrm{a}}$

\begin{tabular}{lcccc}
\hline Entry & Solvent & Temperature & Base & Yield $(\%)^{\mathrm{b}}$ \\
\hline 1 & $\mathrm{DMF}$ & 100 & $\mathrm{~K}_{2} \mathrm{CO}_{3}$ & 60 \\
2 & $\mathrm{DMF}$ & 100 & $\mathrm{KOH}$ & 60 \\
3 & $\mathrm{CH}_{3} \mathrm{CN}$ & 80 & $\mathrm{~K}_{2} \mathrm{CO}_{3}$ & 65 \\
4 & $\mathrm{H}_{2} \mathrm{O}$ & reflux & $\mathrm{KOH}$ & 10 \\
5 & $\mathrm{EtOH}$ & 70 & $\mathrm{~K}_{2} \mathrm{CO}_{3}$ & 30 \\
6 & EtOH & 70 & $\mathrm{KOH}$ & 30 \\
7 & $p$-xylene & 80 & $\mathrm{KOH}$ & 70 \\
8 & $p$-xylene & 80 & $\mathrm{~K}_{2} \mathrm{CO}_{3}$ & $20^{\mathrm{C}}$ \\
9 & $p$-xylene & 80 & $\mathrm{~K}_{2} \mathrm{CO}_{3}$ & $35^{\mathrm{d}}$ \\
10 & $p$-xylene & 80 & $\mathrm{~K}_{2} \mathrm{CO}_{3}$ & 95 \\
11 & $p$-xylene & 80 & $\mathrm{Et}_{3} \mathrm{~N}$ & 85 \\
12 & $p$-xylene & 80 & $\mathrm{Pyridine}^{2}$ & 70 \\
13 & $p$-xylene & 80 & - & 10 \\
\hline
\end{tabular}

${ }^{\text {a }}$ Reaction conditions: phenylethyl alcohol (1.00 mmol), base $(0.50 \mathrm{mmol})$, catalyst $(5 \mathrm{~mol} \%, 0.23 \mathrm{~g})$, solvent $10 \mathrm{~mL}$ for $4 \mathrm{~h}$, air.

${ }^{b}$ Yield determined by $\mathrm{GC}$ analysis. ${ }^{\mathrm{c}}$ in the presence of $\mathrm{CoCl}_{2} \cdot 6 \mathrm{H}_{2} \mathrm{O}$ as a catalyst; ${ }^{\mathrm{d}}$ using $\mathrm{Co}(\mathrm{II})$-chitosan coordination polymer as a catalyst (without reduction of $\mathrm{Co}(\mathrm{II})$ ).

\subsection{General procedure for the oxidation of aromatic alcohols}

Alcohols (1 mmol) were added in a two roundbottomed glass flask containing a mixture of cobaltchitosan (5 mol \%, $0.023 \mathrm{~g}$ ) and $\mathrm{K}_{2} \mathrm{CO}_{3}(0.5 \mathrm{mmol}$, $0.069 \mathrm{~g}$ ) in $10 \mathrm{~mL} p$-xylene. The flask was fitted with a reflux condenser and mixture was heated at $80^{\circ} \mathrm{C}$ with continuous bubbling of air with flow rate of $15 \mathrm{~mL}$ $\mathrm{min}^{-1}$. After completion of the reaction (progress of the reaction followed by TLC), catalyst was separated by an external magnet and the reaction mixture was analyzed by gas chromatography using a CP-Sil- 8 fused silica capillary column.

\section{Results and Discussion}

At first, cobalt (II) on chitosan was immobilized. The dropwise addition of solution of cobalt chloride $\left(\mathrm{CoCl}_{2} \cdot 6 \mathrm{H}_{2} \mathrm{O}\right)$ to chitosan suspension resulted in a light pink coloration, which indicated formation of cobalt (II)-chitosan complex. Then cobalt-chitosan was prepared by chemical reduction of this suspension. The morphology and size of cobalt-chitosan have been investigated by TEM. Figure 1 shows TEM images of catalyst that clearly illustrate the rod-like morphology of cobalt particles. Cobalt particles were dispersed on chitosan and they are very active in the aerobic oxidation.

The chemical composition of cobalt-chitosan was investigated using energy dispersive spectroscopy (EDS) analysis. The EDS analysis clearly illustrated the presence of cobalt in the catalyst (figure 2).

The XPS analysis of cobalt -chitosan was done to obtain information about oxidation state of cobalt particles and their interaction with chitosan (figure 3). The main peaks appeared in survey scan are Co $2 p, C$ s, O $1 \mathrm{~s}$ and $\mathrm{N}$ 1s. In XPS analysis of catalyst, we observed two peaks for cobalt that correspond to Co (0) and Co (II). Co $2 \mathrm{p}_{3 / 2}$ peak of $\mathrm{Co}^{2+}$ species appeared in 781.66 $\mathrm{eV}$ and cobalt metal phase peak appeared in $777.56 \mathrm{eV}$. The ratio of cobalt metallic to cobalt ion was about 60 to 40 . The Co $2 p_{3 / 2}$ binding energy of metallic cobalt in $781.1 \mathrm{eV}$ was shifted to $777.56 \mathrm{eV} . \mathrm{N} 1 \mathrm{~s}$ and $\mathrm{O} 1 \mathrm{~s}$ binding energies of cobalt-chitosan were appeared in 401 and $533.23 \mathrm{eV}$, respectively. According to the literature, $\mathrm{N} 1 \mathrm{~s}$ and $\mathrm{O} 1 \mathrm{~s}$ binding energies of chitosan were appeared in 399.4 and $532.2 \mathrm{eV}$, respectively. ${ }^{53}$ Binding energies of $\mathrm{N} 1 \mathrm{~s}$ and $\mathrm{O} 1 \mathrm{~s}$ were found to be higher than same peaks in chitosan. ${ }^{53}$ These upward shifts indicated decreasing electron density around $\mathrm{O}$ and $\mathrm{N}$ due to electron draining to cobalt. The binding energies of Co $2 p$

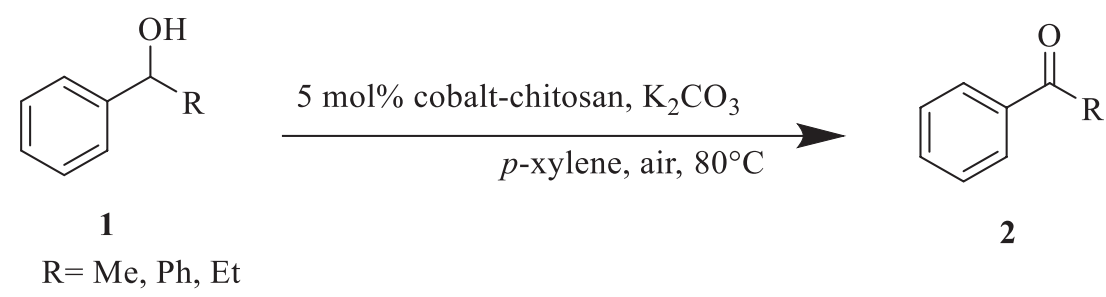

Scheme 1. Oxidation of secondary benzylic alcohols.<smiles>[R]c1ccc(CO)cc1</smiles>

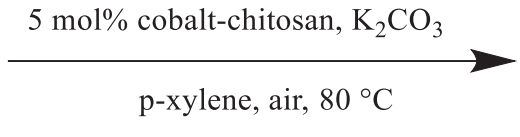<smiles>[R]c1ccc(C=O)cc1</smiles>

Scheme 2. Oxidation of benzylic alcohol with cobalt-chitosan. 
Table 4. Oxidation of alcohols with cobalt-chitosan.

Entry Time (h) Product<smiles>CC(O)c1ccc([O-])cc1</smiles>

10<smiles>Cc1ccc(CO)cc1</smiles>

11<smiles>OCc1ccccc1Cl</smiles>

12<smiles>O=[N+]([O-])c1ccc(CO)cc1</smiles>

13<smiles>CC(O)c1ccccc1</smiles>

14

15

16<smiles>CCCCCCc1ccc(OC)cc1</smiles>

$1: 30$

8<smiles>Cc1ccc(C=O)cc1</smiles>

Table 4. (continued)

Entry substrate Time (h) Product Yield ${ }^{\mathrm{a}}(\%)$

Reaction conditions: alcohol $(1.00 \mathrm{mmol}), \mathrm{K}_{2} \mathrm{CO}_{3}(0.50$ $\mathrm{mmol})$, cobalt-chitosan ( $5 \mathrm{~mol} \%, 0.23 \mathrm{~g}$ ), $p$-xylene $5 \mathrm{~mL}$ at $80^{\circ} \mathrm{C}$, air. ${ }^{\text {a }}$ Yield determined by GC analysis.

in cobalt-chitosan shifted to the lower energy region. These downwards shifts indicated that electron density around cobalt increased since electron receiving from the $\mathrm{O}$ and $\mathrm{N}$ atoms in the chitosan units. So XPS results showed that the Co-N and Co-O coordinate bands were formed and caused to stabilize of Co particles..$^{53,54}$

Figure 4 shows the FT-IR spectra of the cobaltchitosan and chitosan. In chitosan spectrum, N-H and $\mathrm{O}-\mathrm{H}$ stretching vibration appeared in $3448 \mathrm{~cm}^{-1}$. Band at 1653 and $1602 \mathrm{~cm}^{-1}$ displayed the presence of amide and $-\mathrm{NH}_{2}$ group, respectively. Stretching vibration of aliphatic $\mathrm{C}-\mathrm{H}$ groups appeared at $2869 \mathrm{~cm}^{-1}$. Bands in 1422 and $1381 \mathrm{~cm}^{-1}$ region correspond to $\mathrm{CH}_{2}$ and $\mathrm{CH}_{3}$ bending vibration respectively $\mathrm{C}-\mathrm{N}$ stretching vibration appeared in the 920-1200 $\mathrm{cm}^{-1}$ region and overlapped with characteristic absorption bands of saccharide structure. ${ }^{53} \mathrm{C}-\mathrm{O}, \mathrm{O}-\mathrm{H}$ and $\mathrm{C}-\mathrm{N}$ stretching vibration bands of chitosan in catalyst spectrum showed red shift obviously due to interaction of cobalt and chitosan.

Vacuum-dried cobalt-chitosan was employed for the FAAS. The Co concentration obtained using calibration curve was prepared with cobalt solution standards. The cobalt loading in catalyst was determined to be $13 \mathrm{wt} \%$.

The catalytic activity of the cobalt-chitosan was tested in the aerobic oxidation of alkyl arenes. The oxidation of diphenylmethane was performed as a model reaction and the effects of solvent, temperature, time and amount of catalyst were investigated. The results were summarized in table 1 . The best conditions for aerobic oxidation of diphenylmethane were $5 \mathrm{~mol} \%$ catalyst, $1 \mathrm{~mol} \%$ NHPI and in 1, 2-dichlorobenzene at $80^{\circ} \mathrm{C}$ using ambient air as oxidant (table 1, entry 5). Using NHPI as an initiator was necessary to achieve the high conversion in the oxidation of alkyl arenes.

To determine efficiency of catalyst for aerobic oxidation, a large variety of alkyl arenes were subjected to optimized conditions. As shown in table 2, the results showed that the oxidation of alkyl arenes using cobalt-chitosan were produced the corresponding carbonyl compounds selectively in high yields. Oxidation of toluene was produced benzaldehyde. Aerobic oxidation of the reactants with two benzylic sites 


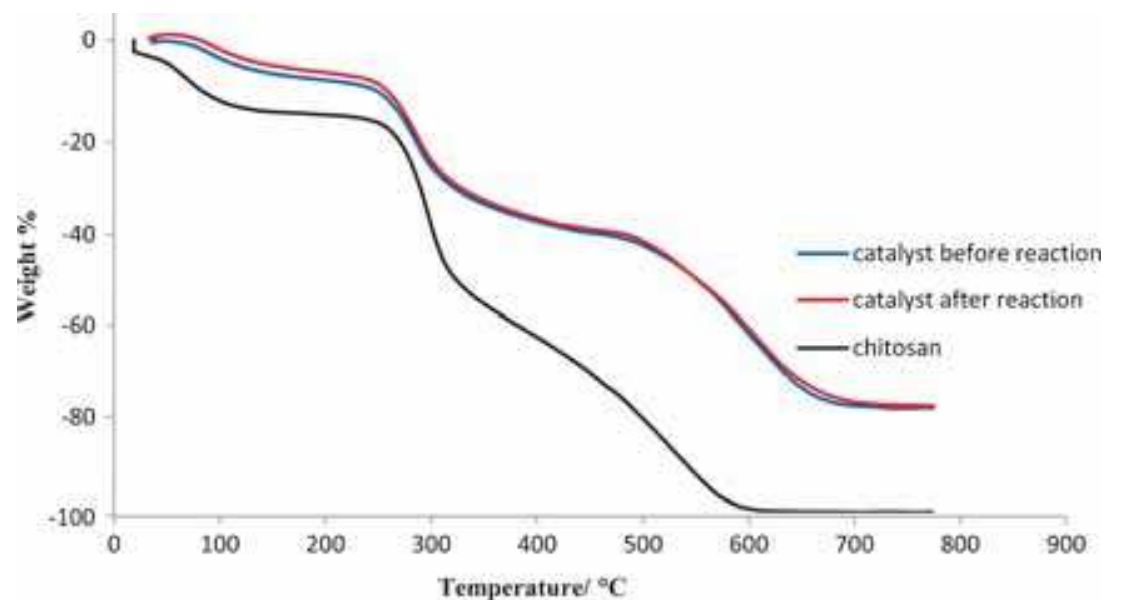

Figure 5. TGA of chitosan catalyst before and after reaction.

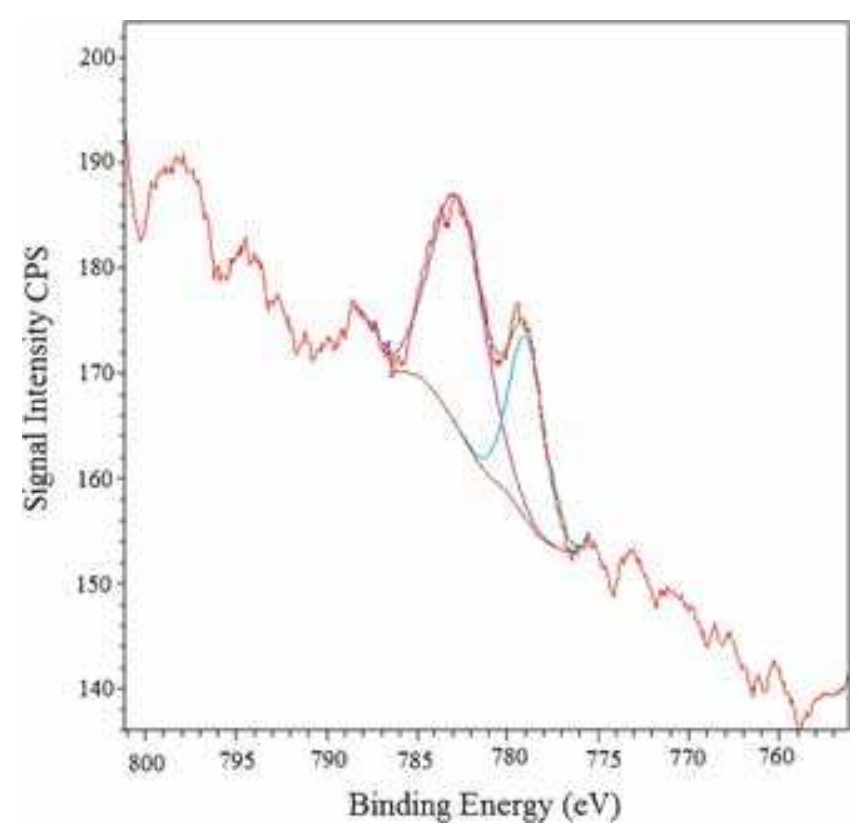

Figure 6. XPS spectrum of cobalt-chitosan after reaction.

was carried out selectively in one position (table 2 , entries 6,7).

In order to further assess the ability of the catalyst, the scope of the aerobic oxidation was further expanded to aromatic alcohols. The oxidation of phenylethyl alcohol was performed as a model reaction. We investigated the effect of solvent on oxidation process. After testing a variety of solvents, $p$-xylene was determined to be the best solvent for this reaction (table 3, entry 10). Oxidation of phenylethyl alcohol with catalyst under air atmosphere did not produce high yield of product at room temperature. The oxidation was progressed by rising temperature and it smoothly was done at $80^{\circ} \mathrm{C}$ under air atmosphere. Interestingly, $\mathrm{CoCl}_{2} \cdot 6 \mathrm{H}_{2} \mathrm{O}$ and cobalt (II)-chitosan coordination polymer showed little activity in oxidation and further improvement

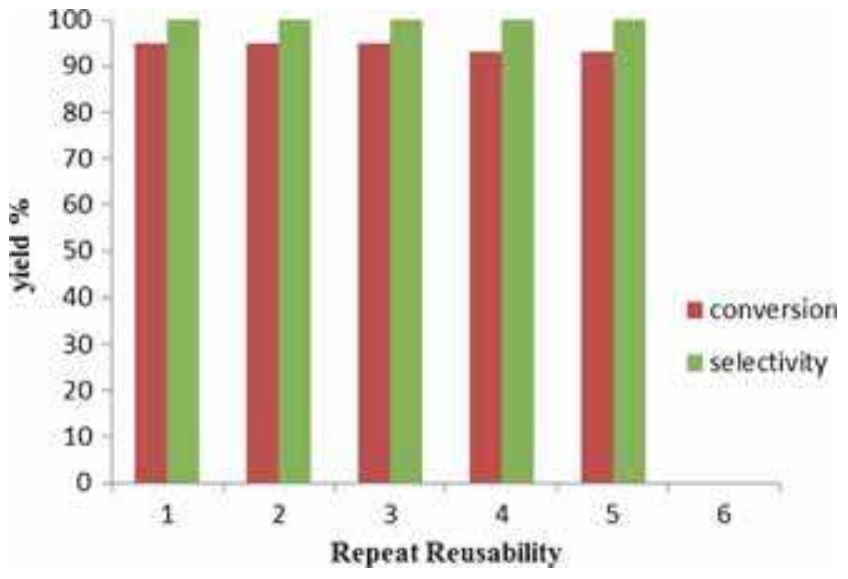

Figure 7. Reusability of the catalyst for oxidation of phenylethyl alcohol by cobalt-chitosan.

could not be achieved with these catalysts (table 3, entries 8 and 9). The optimum conditions are shown in scheme 1.

As shown in scheme 2, these conditions for oxidation of primary benzylic alcohols afforded benzaldehyde derivatives and no over oxidation product was detected. The results are summarized in table 4 . The different rates of oxidation in benzylic alcohols indicate that the substitutions have important role in the reaction. The oxidation reactions were faster with electron-donating group than with electron-withdrawing group. We found that cinnamyl alcohol was oxidized to cinnamaldehyde after $20 \mathrm{~h}$ in $55 \%$ yield (table 4 , entry 15). Cyclohexanol was not converted to cyclohexanone under our reaction conditions and the starting alcohol was recovered. 2Phenylethane-1-ol and 3-phenylpropane-1-ol were converted to corresponding aldehydes in relatively good yields. (table 4, entries 16 and 17).

The thermogravimetric analysis (TGA) curves are shown in figure 5. Different decomposition patterns 
Table 5. Comparison of results in literature and this work for oxidation of benzyl alcohol.

\begin{tabular}{|c|c|c|c|c|c|c|c|}
\hline Entry & Catalyst & Oxidant & Temperature ${ }^{\circ} \mathrm{C}$ & Solvent & Time (h) & Yield (\%) & Reference \\
\hline 1 & cobalt(II)/ZnO & $1.5 \mathrm{MPa} \mathrm{O}_{2}$ & 70 & PEG-600 & 13 & 95 & 37 \\
\hline 2 & $\begin{array}{l}\text { mono transition metal (Co, } \\
\text { Mn, Ni)-substituted Keggin- } \\
\text { phosphomolybdates }\end{array}$ & $\mathrm{H}_{2} \mathrm{O}_{2}$ & 90 & - & 24 & 56.5 & 26 \\
\hline 3 & $\mathrm{Co} / \mathrm{NSC}$ & $\mathrm{O}_{2}$ & 110 & - & 16 & 98 & 41 \\
\hline 4 & cobalt-doped birnessite & $\mathrm{O}_{2}$ & 110 & toluene & 4 & 89 & 55 \\
\hline 5 & $\mathrm{Co}_{3} \mathrm{O}_{4} / \mathrm{AC}$ & $\mathrm{O}_{2}$ & 80 & toluene & 3 & 100 & 24 \\
\hline 6 & cobalt-chitosan & Air, $\mathrm{K}_{2} \mathrm{CO}_{3}$ & 80 & $p$-xylene & 1 & 95 & This work \\
\hline
\end{tabular}

for chitosan and cobalt-chitosan were clearly observed. These results confirmed formation of the new coordination polymer. TGA curves of the catalyst before and after reaction showed that the catalyst was stable under aerobic oxidation reaction conditions (table 4).

XPS spectrum of the catalyst after reaction is shown in figure 6. Two species of cobalt that correspond to $\mathrm{Co}(0)$ and $\mathrm{Co}(\mathrm{II})$ were observed in the spectrum that confirmed that the catalyst was stable in reaction conditions.

The stability and reusability of the catalyst were examined by five sequential oxidation experiments for the model reaction (figure 7 ). In fact, the cobaltchitosan was successfully recycled without any considerable loss of activity and selectivity.

To rule out the possibility of cobalt leaching during the reaction, a hot filtration test consisting of the removal of the catalyst (after $5 \mathrm{~min}$ ) was performed. Upon catalyst removal, no further conversion was observed even after extended time. Moreover, the leaching of cobalt into the aqueous phase has also been checked by the FAAS analysis. The FAAS results showed that cobalt species do not exist in the solution. The absence of leached cobalt is an outstanding result and indicates a strong chelation of the chitosan amino and hydroxyl groups with cobalt species and the cobalt catalyst worked in a heterogeneous manner.

We compared cobalt-chitosan to the studied catalysts mentioned in table 5. Although authors who studied these catalysts used oxidative systems such as $\mathrm{H}_{2} \mathrm{O}_{2}$ or oxygen at high pressure, reaction times they achieved were too long. But using cobalt-chitosan as a catalyst, we found that the reaction completed in a short time and with milder conditions than the other works in some cases. Our catalyst had advantages such as high reusability, easy recoverability by magnet, heterogeneous nature and good selectivity and conversion in the reaction.

\section{Conclusion}

In this work, the formation of cobalt-chitosan using a simple method is described and its catalytic activity was investigated for aerobic oxidation of alkyl arenes and aromatic alcohols. The high activity of catalyst was due cobalt distributed on the surface of chitosan. The catalyst was inexpensive, stable, biodegradable and nontoxic due to the use of chitosan as the support and was readily reused and recovered due to the magnetic property. Elongated Cobalt particles dispersed in the chitosan matrix could be observed in TEM images. The Catalyst showed high activity in the aerobic oxidation of alkyl arenes and aromatic alcohol with negligible amount of leaching of Cobalt into the solution. The activity of the catalyst was affected by factors such as solvent, temperature and base. Generally, the process was eco-friendly, efficient and cost-effective.

\section{Acknowledgments}

We gratefully acknowledge financial support from the Catalyst Center of Excellence (CCE) of Shahid Beheshti University and the Iran National Elites Foundation (INEF).

\section{References}

1. Burke S D and Danheiser R L 1999 In Handbook of Reagents for Organic Synthesis, Oxidizing and Reducing Agents (Chichester UK: John Wiley)

2. Parmeggiani C and Cardona F 2012 Green Chem. 14 547

3. Corey E J and Schmidt G 1979 Tetrahedron Lett. 20399

4. Corey E J and Suggs J W 1975 Tetrahedron Lett. 16 2647

5. Dess D B and Martin J C 1983 J. Org. Chem. 484155

6. Collins J C, Hess W W and Frank F J 1968 Tetrahedron Lett. 93363 
7. Parikh J R and Doering W v E 1967 J. Am. Chem. Soc. 895505

8. Mancuso A J and Swern D 1981 Synthesis 1981165

9. Shylesh S, Schünemann V and Thiel W R 2010 Angew. Chem. Int. Ed. 493428

10. Astruc D, Lu F and Aranzaes J R 2005 Angew. Chem. Int. Ed. 447852

11. Carrettin S, McMorn P, Johnston P, Griffin K and Kiely C J 2003 J. Phys. Chem. Chem. Phys. 51329

12. Shojaei A, Tabatabaeian K, Zanjanchi M A, Moafi H and Modirpanah N 2015 J. Chem. Sci. 127481

13. Ilyas M and Sadiq M 2007 Chem. Eng. Technol. 30 1391

14. Tsunoyama H, Liu Y, Akita T, Ichikuni N, Sakurai H, Xie S and Tsukuda T 2011 Catal. Surv. Asia 15 230

15. Tsunoyama H, Sakurai $H$, Negishi $Y$ and Tsukuda $T$ 2005 J. Am. Chem. Soc. 1279374

16. Vincent T and Guibal E 2002 Ind. Eng. Chem. Res. 41 5158

17. Bianchi C, Porta F, Prati L and Rossi M 2000 Top. Catal. 13231

18. Mallat T and Baiker A 2004 Chem. Rev. 1043037

19. Jiang B, Feng Y and Ison E A 2008 J. Am. Chem. Soc. 13014462

20. Zope B N, Hibbitts D D, Neurock M and Davis R J 2010 Science 33074

21. Zhu J, Faria J L, Figueiredo J L and Thomas A 2011 Chem. Eur. J. 177112

22. Liu W, Li B, Gao C and Xu Z 2009 Chem. Lett. 38 1110

23. Villa A, Campisi S, Giordano C, Otte K and Prati L 2012 ACS Catal. 21377

24. Zhu J, Kailasam K, Fischer A and Thomas J 2011 ACS Catal. 1342

25. Rana B S, Jain S L, Singh B, Bhaumik A, Sain B and Sinha A K 2010 Dalton Trans. 397760

26. Pathan S and Patel A 2013 Appl. Catal. A 45959

27. Mate V R, Shirai M and Rode C V 2013 Catal. Commun. 3366

28. Huang G, Shen L, Luo Z C, Hu Y D, Guo Y A and Wei S J 2013 Catal. Commun. 32108

29. Zhang G and Hanson S K 2013 Org. Lett. 15650

30. Ki Shimizu, Kon K, Seto M, Shimura K, Yamazaki H and Kondo J N 2013 Green Chem. 15418

31. Kuang Y, Nabae Y, Hayakawa T and Kakimoto M 2012 Appl. Catal. A 423-424 52
32. Menini L, Pereira M C, Ferreira A C, Fabris J D and Gusevskaya E V 2011 Appl. Catal. A 392151

33. Shaabani A and Farhangi E 2009 Appl. Catal. A 371148

34. Shaabani A, Keshipour S, Hamidzad M and Shaabani S 2014 J. Mol. Catal. A: Chem. 395494

35. Das B and Chakrabarty R 2011 J. Chem. Sci. 123163

36. Rajabi F, Luque R, Clark J H, Karimi B and Macquarrie D J 2011 Catal. Commun. 12510

37. He J, Wu T, Jiang T, Zhou X, Hu B and Han B 2008 Catal. Commun. 92239

38. Johansson M, Purse B W, Terasaki O and Bäckvall J E 2008 Adv. Synth. Catal. 3501807

39. Xavier K, Chacko J and Mohammed Yusuff K 2004 Appl. Catal. A 258251

40. Ezabadi A, Najafi G R and Hashemi M M 2008 Chin. Chem. Lett. 191277

41. Kuang Y, Nabae Y, Hayakawa T and Kakimoto M -A 2012 Appl. Catal. A 42352

42. Macquarrie D J and Hardy J J E 2005 Ind. Eng. Chem. Res. 448499

43. Muzzarelli C and Muzzarelli R A A 2002 J. Inorg. Biochem. 9289

44. Thatte C S, Rathnam M V and Pise A C 2014 J. Chem. Sci. 126727

45. Karthikeyan G, Anbalagan K and Andal N M 2004 J. Chem. Sci. 116119

46. Huang G, Guo C C and Tang S S 2007 J. Mol. Catal. A: Chem. 261125

47. Sorokin A B, Quignard F, Valentin R and Mangematin S 2006 Appl. Catal. A 309162

48. Huang G, Cai C C, Luo J, Zhou H, Guo Y A and Liu S Y 2008 Can. J. Chem. 86199

49. Crespilho F N, Zucolotto V, Siqueira J, Carvalho A J, Francisco C and Oliveira O 2006 Int. J. Electrochem. Sci. 1151

50. Zeng M, Zhang X, Shao L, Qi C and Zhang X M 2012 J. Organomet. Chem. $\mathbf{7 0 4} 29$

51. Shaabani A and Mahyari M 2013 J. Mater. Chem. 1 9303

52. Shaabani A, Keshipour S, Hamidzad $M$ and Seyyedhamzeh M 2014 J. Chem. Sci. 126111

53. Huai-min G and Xian-su C 2004 Polym. Adv. Technol. 1589

54. Wu N Q, Fu L, Su M, Aslam M, Wong K C and Dravid V P 2004 Nano Lett. 4383

55. Kamimura A, Nozaki Y, Nishiyama $M$ and Nakayama M 2013 RSC Adv. 3468 